\title{
Impact of legislative reform on benefit access and disability duration in workers' compensation: an interrupted time series study
}

\author{
Alex Collie 조 , Dianne Beck, Shannon Elise Gray 두 , Tyler Jeremiah Lane
}

- Additional material is published online only. To view please visit the journal online (http://dx.doi.org/10.1136/ oemed-2019-106063).

School of Public Health and Preventive Medicine, Monash University, Melbourne, Victoria, Australia

\section{Correspondence to}

Prof Alex Collie, School of Public Health and Preventive Medicine, Monash University, Melbourne, VIC 3800, Australia; alex.collie@monash.edu

Received 3 July 2019 Revised 12 November 2019 Accepted 18 November 2019 Published Online First 29 November 2019
Check for updates

(C) Author(s) (or their employer(s)) 2020. No commercial re-use. See rights and permissions. Published by BMJ.

To cite: Collie $A$ Beck D, Gray SE, et al. Occup Environ Med 2020:77:32-39.

\section{ABSTRACT}

Objectives To determine the impact of legislative changes to the New South Wales (NSW) workers' compensation scheme on injured workers access to benefits, insurer claim processing and work disability duration.

Methods Population-based interrupted time series study of workers' compensation claims made in NSW 2 years before and after legislative amendment in June 2012. Outcomes included incidence of accepted claims per 100000 workers, the median and 75th percentile insurer decision time in days, and the median and 75th percentile of work disability duration in weeks. Effects were assessed relative to a comparator of seven other Australian workers' compensation jurisdictions.

Results $n=1069231$ accepted workers' compensation claims were analysed. Claiming in NSW fell 15.3\% following legislative reform, equivalent to 46.6 fewer claims per 100000 covered workers per month. This effect was greater in time loss claims (17.3\%) than medical-only claims (10.3\%). Across models, there were consistent trend increases in insurer decision time. Median work disability duration increased following the legislative reform

Conclusions The observed reduction in access to benefits was consistent with the policy objective of improving the financial sustainability of the compensation scheme. However, this was accompanied by changes in other markers of performance that were unintended, and are suggestive of adverse health consequences of the reform. This study demonstrates the need for care in reform of workers' compensation scheme policy.

\section{BACKGROUND}

Employment injury insurance systems support people during the periods of temporary work disability. While approaches vary dramatically between and within nations, ${ }^{1-3}$ these systems provide some level of income support for people experiencing an episode of work disability. They may also provide or fund services intended to return the disabled worker to employment or to aid recovery.

Engagement with these systems can have a significant impact on the health and employment outcomes of injured and ill workers. Workers can experience interactions with these systems as stressful and this can contribute to poor mental health, loss of work function and increased disability. ${ }^{45}$ Claiming

\section{Key messages}

What is already known about this subject?

- Most nations have employment injury insurance systems to support people during periods of work disability.

- High-quality evaluations of policy reform are important to inform system design and support worker and employer outcomes, but remain rare.

What are the new findings?

- Changes to the workers' compensation scheme in the Australian state of New South Wales designed to improve financial sustainability produced a significant $15.3 \%$ reduction in benefit access, slowed insurer decision making and increased median disability duration.

- Interrupted time series analysis attributes the observed changes to policy reform.

How might this impact on policy or clinical practice in the foreseeable future?

- This study provides new evidence of the intended and unintended consequences of policy reform that impacted on many thousands of injured workers.

- Findings demonstrate the need for substantial care in future reform of such systems.

workers' compensation increases the probability of later welfare benefit receipt. ${ }^{6}$ System administrative processes can impede return to work in some people $^{7}$ and may affect others involved in worker rehabilitation such as healthcare providers, ${ }^{8}$ potentially limiting access to care. ${ }^{9}$

Spending on social insurance, such as workers' compensation and disability insurance, has been growing. In nations such as the USA, Australia, Denmark and Sweden, the share of the population receiving disability insurance benefits has grown in recent decades. ${ }^{10-12}$ Governments have responded by tightening eligibility criteria or reducing benefit generosity. ${ }^{13} 14$ Such reforms can have significant and unanticipated health consequences. Analysis of a Dutch disability reform identified that reductions in benefit generosity were associated with adverse effects on life expectancy, particularly for women with low predisability earnings. ${ }^{13}$ In England, 
eligibility reassessment has been linked with an increase in selfreported mental health problems and suicide. ${ }^{14}$

In Australia, workers' compensation systems provide insurance coverage for temporary disability and medical care for approximately $94 \%$ of the labour force ${ }^{15}$ yet there is a sparse evidence base to support system design. ${ }^{1}$ Time-bound policy changes, such as legislative reform, provide an opportunity for 'natural experiments' that can produce strong evidence of policy impacts. ${ }^{16}$

This study examines the consequences of a substantial legislative reform to the workers' compensation scheme in the Australian state of New South Wales (NSW) that sought to ensure the long-term financial sustainability of the scheme by restricting eligibility, introducing time limits on income support and implementing more stringent work capacity assessment. Aspects of the reform targeted workers with occupational diseases and mental health conditions. Consistent with the policy objectives of the reforms, we hypothesise a reduction in the number of workers accessing the NSW workers' compensation scheme in the period after reform. Based on prior studies that have demonstrated increases in the time taken by insurers to adjudicate claims following legislative reform, ${ }^{17}$ and the adverse impacts of slower decision making on return to work, ${ }^{45}$ we hypothesise that the reforms increased insurer decision time and the duration of disability among workers with accepted claims. Finally, we hypothesise that workers with occupational disease and mental health conditions will be disproportionately affected by the reforms.

\section{METHODS}

\section{Study design}

This is a retrospective population-based interrupted time series (ITS) study.

\section{Setting}

Australia has a resident population of approximately 25 million people, a working age population of 16.2 million, and a labour force of 12.3 million. ${ }^{18}$

Australian workers' compensation schemes are principally organised on a geographical basis, with each state and territory having a single compulsory scheme. Commonwealth (national) schemes also operate for federal government employees, some large employers, maritime workers and defence force personnel. Insurance claims management is performed either by private sector insurers or directly by the government authorities.

\section{State of NSW legislative reform}

In June 2012, the NSW Workers' Compensation Legislation Amendment Act (2012) ('The Act') came into effect. The Act made multiple changes to the scheme's structure and operation, which are summarised in table 1.

The primary policy objective of this legislative reform was to improve the long-term financial sustainability of the scheme. This was intended to be achieved by reducing the generosity of benefits and services and restricting access to the scheme for certain groups of workers, thus reducing overall expenditure. A second objective was to improve return to work rates of workers with accepted claims, by introducing financial disincentives for not returning to work if the worker was assessed to have some work capacity. A new regimen of work capacity assessments was introduced to implement this objective. The reforms provided the regulator and insurers with additional powers to make claims decisions that affected treatment and income benefits, and limited recourse to appeals by the worker. Most of the reforms came into effect on 19 June 2012.

The reforms had a significant impact on the finances of the scheme. A subsequent statutory review demonstrated a \$AUD5

Table 1 Summary of the 2012 reforms to New South Wales workers' compensation legislation

\begin{tabular}{l} 
Area of reform \\
\hline Eligibility \\
Income benefits
\end{tabular}
Description

Definitions were tightened such that workers with occupational diseases, mental health conditions, heart attack and stroke were only eligible if employment was the main contributing factor to the condition/disease.

Workers who were injured on the way to or from work were required to demonstrate a real and substantive connection between employment and the accident/injury.

Income benefits

Weekly income payments were limited to a maximum of 5 years duration except for the most seriously injured workers rather than continuing to retirement age.

New time limit on benefits for workers with full work capacity of 13 weeks.

Benefits for workers with partial work capacity were time limited to 130 weeks.

The maximum weekly benefit increased from \$AUD1775 to \$AUD1838 and was indexed annually.

Income benefits were ceased at statutory retirement age (65 years) rather than continuing for up to 12 months postretirement. Removal of entitlements to lump sum payments for pain and suffering.

Threshold for lump sum payments for permanent impairment from physical injury changed from $1 \%$ whole person impairment to $>10 \%$.

Medical treatment

Suitable employment

Assessment

Powers of regulator and insurers
Time limits on payments for medical treatment were introduced, restricting payments to 12 months after compensation claim is made, or 12 months from the date of the last income payment, whichever is the latter.

Definition of suitable employment was changed to exclude consideration of whether work is available or available close to the workers' place of residence.

Restriction to a single assessment to determine whole person impairment

Provided that work capacity decisions were made by the insurer and were not eligible for review.

Provided the regulator with the power to determine the necessity for medical treatment, the nature of medical treatment and the appropriateness of the treatment provider.

Workplace inspectors (employed by regulator) provided with the power to issue legally binding improvement notices to employers not meeting obligations, with penalties payable.

Dispute resolution and legal assistance Establishment of the WorkCover Independent Review Office (WIRO) to deal with complaints about insurers made by workers or employers.

Establishment of the Independent Legal Assistance and Review Service under WIRO to facilitate claimant access to free legal advice.

Claimants required to fund their own legal costs in most disputes. 
billion improvement in financial position, moving from a \$AUD4 billion unfunded liability to a \$AUD1 billion surplus within two years. ${ }^{19}$ The reforms have been the subject of multiple statutory reviews. ${ }^{19} 20$ However, the long-term impacts have not been formally evaluated.

\section{Data sources}

Data for this study were derived from the National Dataset for Compensation based Statistics. The database includes individual person-level data for every accepted workers' compensation claim since the 2003/2004 financial year and is updated annually. Data fields include information related to the worker and their occupation, the compensation claim, the condition leading to the claim as well as claim outcome. The database includes Australian Bureau of Statistics labour force denominator data suitable for calculating claim rates. National standard occupational, ${ }^{21}$ industry ${ }^{22}$ and type of condition ${ }^{23}$ coding are used. The database has been used previously to examine differences in disability duration between jurisdictions, ${ }^{1}$ to characterise highrisk occupational cohorts ${ }^{24}$ and to examine the impact of policy change. ${ }^{17}$

\section{Participants}

Claim-level data were extracted for people with accepted claims for a 2-year period before and after the month of the NSW legislative reform (June 2012). As the Act took effect in the middle of June, this month was excluded from analysis.

Inclusion criteria were: (1) accepted workers' compensation claim; (2) date of injury between 1 June 2010 and 30 May 2012 or between 1 July 2012 and 30 June 2014; and (3) claim lodgement in one of the following eight Australian workers' compensation jurisdictions: NSW, Victoria, Queensland, Western Australia, Tasmania, South Australia, Northern Territory, Australian Capital Territory. Denied and pending claims were excluded. Three Commonwealth schemes for federal government employees, maritime workers and defence services personnel were not included. Participants were then divided into two groups based on the jurisdiction in which they accessed workers' compensation, being (1) NSW and (2) all other jurisdictions, collectively acting as a comparison group. Review of national legislative changes revealed that some of the comparator jurisdictions had substantial legislative reform before) or after the study period but no equivalent scheme wide reforms occurred during the study period.

To assess reform impact by type of injury/disease, claims were further separated into groups including (1) occupational diseases including heart attack and stroke; (2) mental health conditions and (3) all other injuries.

\section{Outcomes}

Access to benefits

Defined as the monthly incidence of accepted workers' compensation claims per 100000 workers, as per prior studies. ${ }^{24} 25$ Calculated by dividing the number of new accepted claims per calendar month by the number of covered workers. In addition to all accepted claims, rates were calculated for time loss claims (those with at least one day of compensated wage replacement) and medical-only claims (those for which only medical or treatment expenses had been paid but without time loss).

\section{Insurer claim processing}

Defined as the median number of days between the date of claim lodgement by the employer and the date of claim acceptance by the insurer, for all claims accepted within a calendar month. This metric reflects the amount of time the insurer takes to decide whether to accept, deny or reject a workers' compensation claim. Prior studies demonstrate that insurer claims processing delays are associated with delayed return to work. ${ }^{26}$ We also examined the 75 th percentile to better enable identification of changes in the higher end of the distribution. ${ }^{17}$

Table 2 Characteristics of study groups

\begin{tabular}{|c|c|c|c|c|}
\hline & \multicolumn{2}{|c|}{$\begin{array}{l}\text { Period before reform } \\
\text { (June } 2010 \text { to May 2012) }\end{array}$} & \multicolumn{2}{|c|}{$\begin{array}{l}\text { Period after reform } \\
\text { (July } 2012 \text { to June 2014) }\end{array}$} \\
\hline & New South Wales & Comparator jurisdictions & New South Wales & Comparator jurisdictions \\
\hline Total number of claims & $245385(100.0)$ & $337559(100.0)$ & $183016(100.0)$ & $303271(100.0)$ \\
\hline \multicolumn{5}{|l|}{ Gender } \\
\hline Female & $92150(37.6)$ & $116140(34.4)$ & $64502(35.2)$ & $106624(35.2)$ \\
\hline Male & $153235(62.5)$ & $221418(65.6)$ & $118514(64.8)$ & $196647(64.8)$ \\
\hline \multicolumn{5}{|l|}{ Age at claim lodgement } \\
\hline $16-35$ years & $92780(37.8)$ & $129753(38.4)$ & $70163(38.3)$ & $113353(37.4)$ \\
\hline $36-50$ years & $86416(35.2)$ & $119590(35.4)$ & $62385(34.1)$ & $104433(34.4)$ \\
\hline $51-100$ years & $65737(26.8)$ & $87618(26.0)$ & $50156(27.4)$ & $85087(28.1)$ \\
\hline \multicolumn{5}{|l|}{ Injury type } \\
\hline Musculoskeletal conditions & $136740(55.7)$ & $188793(55.9)$ & $102732(56.1)$ & $173280(57.1)$ \\
\hline Fractures & $12479(5.1)$ & $23207(6.9)$ & $9665(5.3)$ & $22018(7.3)$ \\
\hline Other traumatic & $72787(29.7)$ & $92912(27.5)$ & $55969(30.6)$ & $79160(26.1)$ \\
\hline Neurological conditions & $6997(2.9)$ & $9975(3.0)$ & $3833(2.1)$ & $9064(3.0)$ \\
\hline Mental health conditions & $8674(3.5)$ & $12107(3.6)$ & $5505(3.0)$ & 10967 (3.6) \\
\hline Other diseases & $5394(2.2)$ & $9438(2.8)$ & $4075(2.2)$ & $7763(2.6)$ \\
\hline Other claims & $2314(0.9)$ & $1127(0.3)$ & $1237(0.7)$ & $1019(0.3)$ \\
\hline \multicolumn{5}{|l|}{ Claim type } \\
\hline Time loss & $147328(60.0)$ & $221531(65.6)$ & $103982(56.8)$ & $206585(68.1)$ \\
\hline Medical only & $98057(40.0)$ & $116028(34.4)$ & $79033(43.2)$ & $96686(31.9)$ \\
\hline
\end{tabular}


Table 3 Effects of the 2012 amendments on outcomes, controlled for other Australian jurisdictions

\begin{tabular}{|c|c|c|c|c|c|c|c|c|}
\hline \multirow[b]{2}{*}{ Outcome 1} & \multicolumn{2}{|c|}{$\begin{array}{l}\text { Before reform } \\
\text { (June } 2010 \text { to May 2012) }\end{array}$} & \multicolumn{2}{|c|}{$\begin{array}{l}\text { After reform } \\
\text { (July } 2012 \text { to June 2014) }\end{array}$} & \multicolumn{2}{|c|}{ Median-level change $(99 \% \mathrm{Cl})$} & \multicolumn{2}{|c|}{$\begin{array}{l}\text { Median trend change } \\
(99 \% \mathrm{Cl})\end{array}$} \\
\hline & \multicolumn{4}{|c|}{ Median monthly claim rate per 100000 workers (IQR) } & \multicolumn{4}{|c|}{ Interrupted time series analyses } \\
\hline \multicolumn{3}{|l|}{ All accepted claims } & & & & & & \\
\hline New South Wales & 343.4 & $(312.9-354.6)$ & 237.8 & $(221.1-248.9)$ & $-46.6^{*}$ & $(-63.2$ to -30.1$)$ & $-0.3 \dagger$ & $(-1.4$ to 0.9$)$ \\
\hline Comparator Jurisdictions & 214.9 & $(196.3-220)$ & 180.1 & $(169.6-188.7)$ & -7.7 & $(-19.4$ to 4.0$)$ & -0.6 & $(-1.4$ to 0.2$)$ \\
\hline \multicolumn{9}{|l|}{ Time loss claims } \\
\hline New South Wales & 205.0 & $(185-215.3)$ & 135.3 & $(125.5-140.8)$ & $-31.6^{*}$ & $(-46.1$ to -17.1$)$ & -0.4 & $(-1.6$ to 0.8$)$ \\
\hline Comparator Jurisdictions & 141.7 & $(129.1-145)$ & 122.5 & $(116.4-127.4)$ & -4.7 & $(-15.0$ to 5.5$)$ & -0.4 & $(-1.3$ to 0.4$)$ \\
\hline \multicolumn{9}{|l|}{ Medical only claims } \\
\hline New South Wales & 137.0 & $(126.2-139.2)$ & 103.0 & $(95.3-107.9)$ & $-12.5^{*}$ & $(-17.1$ to -7.9$)$ & 0.1 & $(-0.2$ to 0.4$)$ \\
\hline Comparator Jurisdictions & 72.9 & $(66.9-75.1)$ & 56.7 & $(53.3-60.3)$ & -4.4 * & $(-7.6$ to -1.2$)$ & -0.1 & $(-0.3$ to 0.1$)$ \\
\hline
\end{tabular}

IQR, Interquartile Range.

\begin{tabular}{|c|c|c|c|c|c|c|c|c|}
\hline Outcome 2 & \multicolumn{4}{|c|}{ Insurer decision time (days) } & \multicolumn{4}{|c|}{ Interrupted time series analyses } \\
\hline \multicolumn{9}{|l|}{ Median (IQR) } \\
\hline New South Wales & 6 & $(2-17)$ & 7 & $(4-22)$ & $1.2^{*} \dagger$ & (0.5 to 1.8$)$ & $0.1^{*}$ & (0.0 to 0.1$)$ \\
\hline Comparator Jurisdictions & 5 & $(2-13)$ & 5 & $(2-12)$ & $-0.8^{*}$ & $(-1.3$ to -0.3$)$ & $0.0^{*}$ & $(-0.1$ to 0.0$)$ \\
\hline \multicolumn{9}{|l|}{ 75th percentile } \\
\hline New South Wales & 17 & & 22 & & 2.1 & $(-2.7$ to 6.9$)$ & $0.4^{*}$ & (0.0 to 0.8$)$ \\
\hline Comparator jurisdictions & 13 & & 12 & & -1.0 & $(-4.3$ to 2.2$)$ & 0.0 & $(-0.2$ to 0.2$)$ \\
\hline
\end{tabular}

IQR, Interquartile Range.

\begin{tabular}{|c|c|c|c|c|c|c|c|c|}
\hline \multirow{2}{*}{$\begin{array}{l}\text { Outcome } 3 \\
\text { Median (IQR) }\end{array}$} & \multicolumn{4}{|c|}{ Duration of disability (weeks) } & \multicolumn{4}{|c|}{ Interrupted time series analyses } \\
\hline & & & & & & & & \\
\hline New South Wales & 1.8 & $(0.6-7.0)$ & 2.0 & $(0.7-7.3)$ & $0.5^{*}$ & (0.2 to 0.8$)$ & 0.0 & $(0.0$ to 0.0$)$ \\
\hline Comparator jurisdictions & 3.0 & $(0.8-12.0)$ & 3.2 & $(0.8-12.7)$ & $-0.3^{*}$ & $(-0.5$ to -0.2$)$ & 0.0 & (0.0 to 0.0$)$ \\
\hline \multicolumn{9}{|l|}{ 75th percentile } \\
\hline New South Wales & 7.0 & & 7.3 & & $1.2^{*} \dagger$ & (0.7 to 1.7$)$ & $0.1^{*}$ & (0.0 to 0.1$)$ \\
\hline Comparator jurisdictions & 12.0 & & 12.7 & & $-1.2^{*}$ & $(-1.5$ to -0.8$)$ & 0.0 & $(0.0$ to 0.0$)$ \\
\hline
\end{tabular}

${ }^{*} \mathrm{P}<0.01$.

†Inconsistent results between controlled and uncontrolled analyses.

IQR, Interquartile Range.

\section{Disability duration}

Defined as the median number of weeks for which income benefits have been paid for claims accepted within a given calendar month, censored to a maximum of 104 weeks. This metric has been used to assess disability duration in multiple prior studies. $^{12427}$ We also calculated the 75 th percentile to enable examination of any changes in the higher end of the distribution.

\section{Data analysis}

Descriptive statistics including counts, percentages, medians and IQRs were used to examine outcomes before and after legislative reform in both NSW and the comparator jurisdictions.

ITS analysis was used to compare outcomes before and after legislative reform. Aggregate data of monthly outcomes for the NSW and comparator cohorts were compiled. Changes were evaluated by comparing the outcomes between cohorts using a generalised least-squares regression. ${ }^{28}$ In total, 96 data points were included in the regression model, including 24 monthly data points before and after the NSW reform for both NSW and the comparator cohorts. To account for seasonality, we tested sets of harmonic terms (six sine and six cosine), retaining those that were statistically significant at $\mathrm{p} \leq 0.05 .^{29}$ Rather than coerce the model to fit seasonality in both the exposure and comparator group, each group retained its own set of terms. We adjusted for residual autocorrelation by fitting the data to autoregressive-moving average models based on correlated residuals observed in Autocorrelation Function and Partial Autocorrelation Function plots. ${ }^{28}$ For each analysis, all possible models were compared on Akaike information criterion. Due to the multiple comparisons and increased risk of type 1 errors, significance was set at $\mathrm{p} \leq 0.01$.

ITS results are reported as level changes, affecting the time series' intercept and trend changes, affecting the slope. We conducted each analysis both with (controlled) and without the comparator (uncontrolled). Where results were consistent in terms of significance and direction of effect, we report the results of controlled analyses Where inconsistent, we report the results with more caution and investigate potential sources of history bias or independent changes within the comparator jurisdictions. ${ }^{30}$ In supplementary analysis, we compared median claim incidence, median insurer decision time and median disability duration between injury/disease groups between the NSW and comparator jurisdictions.

Seasonally adjusted ITS trend lines were plotted over monthly data points using code adapted from the ITS tutorial in Bernal et al. ${ }^{16}$ Analyses were conducted in $\mathrm{R}^{31}$ using RStudio ${ }^{32}$ with the following packages: the tidyverse for data manipulation and plotting, nlme for generalised least squares regression analyses, zoo for date creation, and the see and ggpubr packages for additional plotting. 

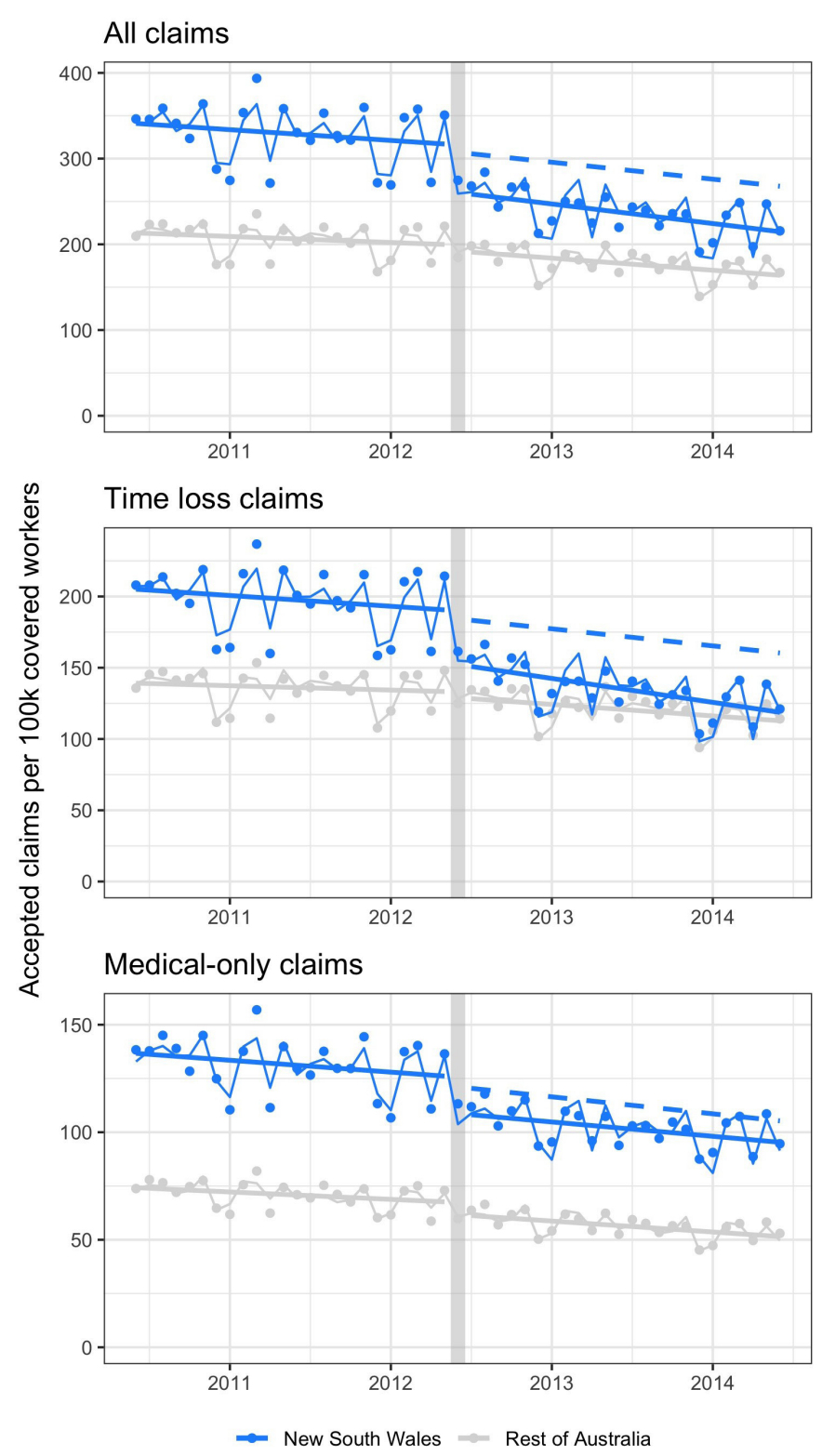

Figure 1 Mean monthly claim incidence in New South Wales (blue) and Comparator Jurisdictions (grey), June 2010 to July 2014 for all claims, time loss claims and medical-only claims. Dotted blue lines=counterfactual.

\section{RESULTS}

\section{Characteristics of workers' compensation claimants}

Claims totalled 1069 231, comprising 428401 (40.1\% of total) claims from NSW and 640830 (59.9\%) claims from comparator jurisdictions (table 2). Nearly two-thirds of cases in both the groups were male, while the age distribution was similar between groups. The most common conditions were musculoskeletal, followed by other traumatic injury. Fractures, mental health conditions, occupational disease and neurological conditions were in the minority. The majority of claims in both groups involved time loss, although these were slightly more common in comparator jurisdictions.

\section{Access to benefits}

Following legislative reform, there was an overall reduction in the rate of accepted workers' compensation claims in NSW. While the median monthly incidence reduced by 106.6 claims per 100000 workers between pre and postreform periods, ITS analysis showed a $15.3 \%$ reduction in the time series intercept coinciding with reform implementation, equivalent to 46.6 fewer claims per 100000 covered workers per month (table 3 and figure 1). ITS revealed that the rate of reduction in time loss claims in NSW in the month following reform was higher at $17.3 \%$ or an estimated 31.6 fewer claims per 100000 workers per month. The reduction in medical-only claims was less but still statistically significant at $10.3 \%$ or 12.5 fewer claims per 100000 workers per month. In comparator jurisdictions, there was a significant reduction of 4.4 medical-only claims per 100000 workers per month, thought plotted results suggest that this was a marginal change. No changes in trend were observed in the controlled analyses for either NSW or comparator jurisdictions.

\section{Insurer claim processing}

Median and 75th percentile insurer decision times increased in NSW post-reform and remained static or decreased in comparator jurisdictions. ITS analysis comparing the pre and post-reform time series revealed a statistically significant level increase in the median insurer decision time in NSW of 1.2 days coinciding with legislative reform, equating to a change of $20 \%$ from the prereform period. This was accompanied by a significant trend increase of 0.1 days per month (table 3 and figure 2). In uncontrolled models, the level increase in median insurer decision time in NSW was smaller at 0.4 days and was non-significant (online supplementary table 1). In contrast, comparator jurisdictions recorded a statistically significant level decrease of 0.8 days.

A similar pattern was observed in ITS analysis of the 75 th percentile of insurer decision time, in which there was a nonsignificant level increase of 2.1 days in NSW accompanied by a statistically significant 0.8 days per month trend increase. No significant level or trend changes in the 75 th percentile were observed in the comparator jurisdictions. Note that for NSW the 2011 data were excluded for non-linear patterns in the data that appeared unrelated to data in the rest of the time series.

\section{Disability duration}

Median and 75th percentile disability duration increased in both NSW and comparator jurisdictions post-reform. ITS analysis comparing the pre and post-reform time series revealed that there was statistically significant level increase in the median disability duration of 0.5 weeks in NSW following the legislative reform (table 3 and figure 2), equivalent to a $28.6 \%$ increase. In contrast, comparator jurisdictions recorded a statistically significant level decrease of 0.3 weeks. Accordingly, there were substantial differences in effect magnitudes between controlled and uncontrolled analyses.

Among the 75 th percentile of disability duration, there were significant trend increases of 0.1 weeks per month. Results on level changes were inconsistent between controlled and uncontrolled analysis.

\section{Outcomes by nature of injury or disease}

ITS results by nature of injury/disease group are presented in online supplementary table 2 . ITS analysis revealed that median claim incidence decreased by $36.5 \%$ in occupational disease, $25.9 \%$ in mental health condition and $13.1 \%$ in all other injury groups. All of these level changes were statistically significant. For mental health condition claims the median insurer decision time increased by $65.5 \%$ and the median disability duration increased by $92.1 \%$ immediately following reform. Level changes on insurer decision time and disability duration were 

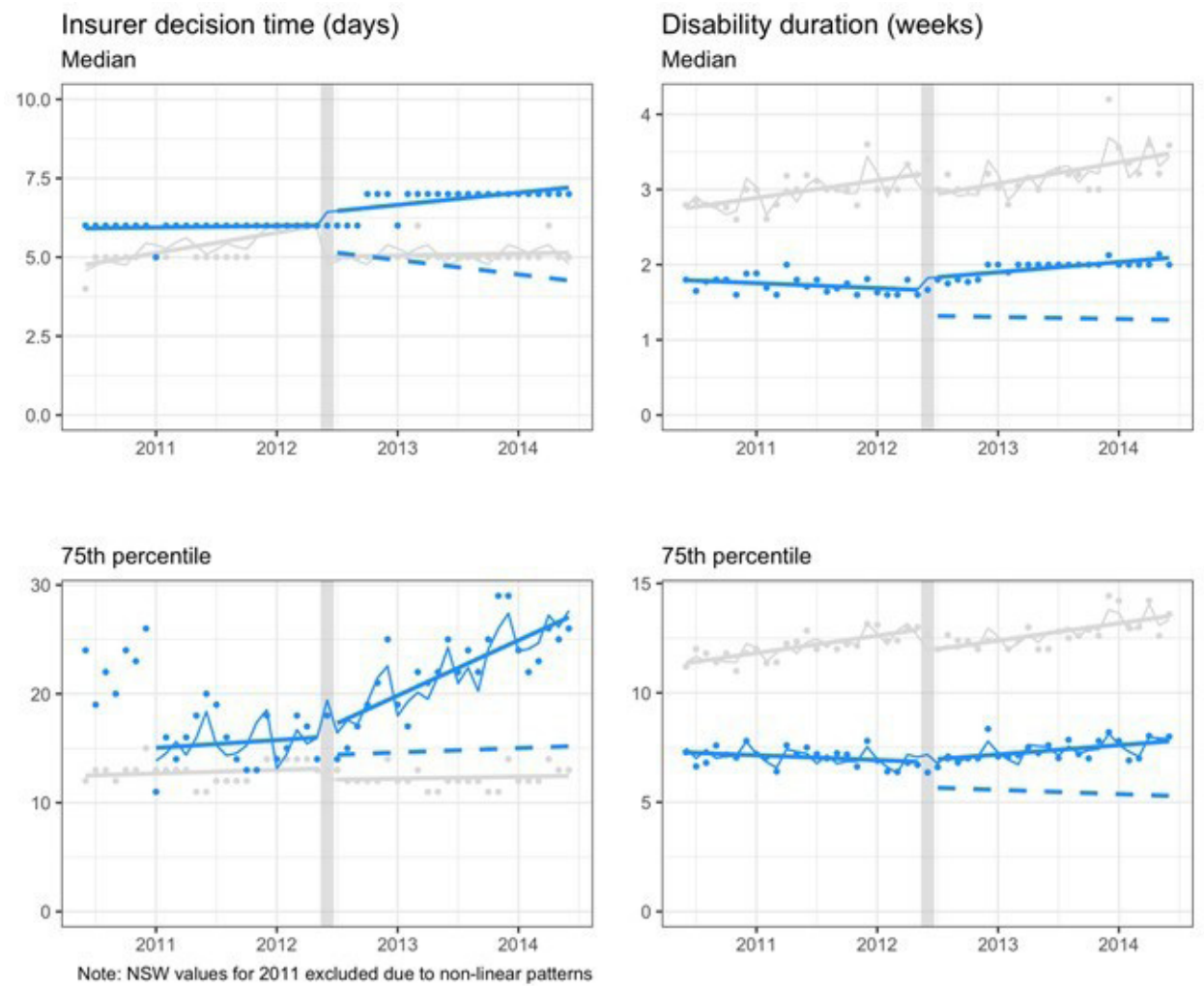

- All other jurisdictions - New South Wales

Figure 2 Median and 75th percentile insurer claim processing and disability duration time in New South Wales (blue) and Comparator Jurisdictions (grey), June 2010 to July 2014. Dotted blue lines=counterfactual.

non-significant for occupational disease and other injury groups, or inconsistent between controlled and uncontrolled analyses.

\section{DISCUSSION}

Legislative reforms to the NSW workers' compensation scheme in 2012 resulted in a large and significant reduction in the number of injured and ill workers having their claims accepted. The magnitude of this policy effect was larger in claims that involved time loss than in claims in which the worker was seeking treatment or medical expenses only. Following the reforms, insurer decisions took longer and the duration of disability for injured workers with accepted claims increased significantly. Reductions in claim acceptance were larger in workers with occupational disease and mental health conditions than workers with other injuries, and there was also a significant increase in disability duration among workers with mental health condition claims. Overall, the findings demonstrate a direct connection between the implementation of the legislative reforms in July 2012 and changes in three outcomes that are important markers of workers' compensation scheme performance. Findings also demonstrate that the impacts of legislative reforms were not evenly distributed and that workers with occupational disease and mental health conditions were disproportionately affected. Despite the pervasive nature of employment injury insurance schemes in developed economies, few studies have examined the impact of legislative reform on worker and scheme relevant outcomes. One Finnish study observed an improvement in return to work and work participation among injured and ill workers following legislative amendments requiring employers to report episodes of extended sickness absence to occupational health services. ${ }^{33}$ Another Finnish study noted workers who accessed part-time sick leave in the first 12 weeks after work disability (enabled by changes in legislation) had improved return to work outcomes and a reduction in full disability retirement compared with workers who accessed full-time sick leave. ${ }^{34}$ Studies in Denmark, Sweden and England have described the adverse impacts of restricting access to benefits on people with work disability. ${ }^{12-14}$ Significant reductions in access to benefits were reported in two studies following tightening of eligibility in USA workers' compensation schemes during the 1990s. ${ }^{35} 36$ There have also been studies of the health impact of legislative reform in other forms of injury compensation such as road traffic crash insurance schemes. ${ }^{3738}$ While the findings of the current study support these prior studies, the unique nature of Australian workers' compensation schemes makes it difficult to generalise to jurisdictions with very different policy settings. Findings are most relevant to jurisdictions with similar workers' compensation arrangements and policy features, including the rest of Australia, Canada, Hong Kong and some southern European nations.

Taken together, these studies suggest that reforms to injury and disability compensation schemes that increase access to benefits are linked with improvements in the health of claimants, whereas reforms that restrict access can have adverse health impacts. Efforts to restrict access require introduction or extension of bureaucratic processes such as medical and functional capacity assessment, which have been associated with negative claimant experience and poor mental health. ${ }^{4}$ The introduction of extra processes can delay decision-making and introduce the potential for disputation, which has also been linked with adverse impacts. ${ }^{39}$ Additional bureaucracy may increase the 'burden of proof' of the injured person to demonstrate the veracity of their claim, ${ }^{4}$ which has been associated with reductions in the perceived fairness of benefit processes, which in turn has been linked with claimant health. ${ }^{40}$ 
Recent system-level studies extend these specific findings and suggest that the relationship between policy reform, compensation scheme performance and worker health is complex, dynamic and can produce unintended health impacts. ${ }^{41}$

In prior studies, we have attributed increases in insurer decision time to increased insurer administrative burden flowing from legislative amendment, ${ }^{17}$ and have observed associations between more complex injuries and longer decision times ${ }^{26}$ We and others have observed that workers with more complex conditions typically have longer disability duration, ${ }^{1}$ but increases in duration may also arise from changes in administrative processes that lead to delays in decisions ${ }^{42}$ or increased worker stress resulting from tightening of benefit access. ${ }^{14}$ These prior studies suggest multiple potential causal mechanisms for the observed increases in insurer decision time and disability duration following the 2012 reforms. While our analysis does not allow us to differentiate between the relative contribution of these mechanisms to the observed change in outcomes, this prior evidence suggests that all may stem from legislative reform of the type undertaken in NSW in 2012.

The NSW legislative reforms took place during a period of economic recovery following the global financial crisis. Prior studies have shown decreases in rates of workers' compensation claims during periods of recession, followed by gradual increases during recovery. This is the opposite pattern to that observed in our study, adding further weight to our conclusion that the change in claim incidence in NSW was due to policy reform to the workers' compensation system.

Strengths of the current study include the use of populationlevel data and a robust quasi-experimental study design. The ITS method enables attribution of the observed changes in outcomes to the policy intervention. Features of our analysis include use of both historical and contemporaneous comparators, testing effects in both controlled and uncontrolled analyses, and adjustment for seasonality and autocorrelation. These adjustments are not able to control for all co-occurring events, for example, changes in comparator jurisdictions that were not observed by the research team. Although outcome measures have been used as indicators of scheme performance in prior studies, we were not able to examine important indicators of function and disability such as self-rated health, work ability or health service utilisation. We use duration of income benefits as a proxy for disability duration as per prior studies, however, we note that some of the NSW reforms may influence income benefits while not affecting disability duration (eg, inability to review insurer work capacity decisions). Our study design also did not allow us to disaggregate the relative contributions of the many changes introduced by the NSW legislative reforms.

\section{CONCLUSION}

We observed large and significant changes to three important markers of workers' compensation scheme performance linked to a major legislative reform in the Australian state of NSW in 2012. The observed reduction in access to benefits was anticipated and consistent with the policy objective of improving the financial sustainability of the compensation scheme. However, this was accompanied by changes in other markers of performance that were unintended, and are suggestive of adverse consequences of the reform. Workers with occupational disease or mental health conditions were disproportionately affected by the reforms. Legislative change is a tool commonly used by governments to influence the performance of benefit and compensation schemes. This study provides evidence that can support future reform in Australian workers' compensation schemes, and demonstrates the need for care in legislative reform to other benefit schemes internationally.

Twitter Alex Collie @axcollie and Tyler Jeremiah Lane @DrTLane

Contributors $A C$ and TJL conceived the study. TJL and DB conducted the analyses with input from AC and SEG. AC drafted the manuscript. All authors reviewed the data analysis, read and approved the final manuscript.

Funding This project was funded by Safe Work Australia and Worksafe Victoria through a grant to the first author. The study also received funding from the Australian Research Council via a Discovery Project Grant to the first author (DP190102473)

Disclaimer This publication uses data supplied by Safe Work Australia and has been compiled in collaboration with state, territory and Commonwealth workers' compensation regulators. The views expressed are the authors and are not necessarily the views of Safe Work Australia or the state, territory and Commonwealth workers' compensation regulators.

Competing interests None declared.

Patient consent for publication Not required.

Ethics approval This study received ethics approval from the Monash University Human Research Ethics Committee on 14 October 2014.

Provenance and peer review Not commissioned; externally peer reviewed.

Data availability statement All data relevant to the study, and $R$ analysis code, are available via figshare at https://monash.figshare.com/projects//mpact_ of_legislative_reform_on_benefit_access_and_disability_duration_in_workers compensation_an_interrupted_time_series_study/71678.

\section{ORCID iDs}

Alex Collie http://orcid.org/0000-0003-2617-9339

Shannon Elise Gray http://orcid.org/0000-0002-8029-6838

Tyler Jeremiah Lane http://orcid.org/0000-0001-6089-1827

\section{REFERENCES}

1 Collie A, Lane TJ, Hassani-Mahmooei B, et al. Does time off work after injury vary by jurisdiction? A comparative study of eight Australian workers' compensation systems. BMJ Open 2016:6:e010910.

2 Lippel K, Lotters F. Public Insurance Systems: A Comparison of Cause-Based and Disability-Based Income Support Systems. In: Loisel P, Anema JR, eds. The role and influence of care providers on work disability. Springer, 2013: 183-202.

3 International Labour Organisation. World social protection report 2017-2019: universal social protection to achieve sustainable development goals. Geneva: International Labour Office, 2017

4 Kilgour E, Kosny A, McKenzie D, et al. Interactions between injured workers and insurers in workers' compensation systems: a systematic review of qualitative research literature. J Occup Rehabil 2015;25:160-81.

5 Grant GM, O'Donnell ML, Spittal MJ, et al. Relationship between stressfulness of claiming for injury compensation and long-term recovery: a prospective cohort study. JAMA Psychiatry 2014;71:446-53.

6 O'Leary P, Boden LI, Seabury SA, et al. Workplace injuries and the take-up of social security disability benefits. Soc Secur Bull 2012;72:1-17.

7 Bartys S, Frederiksen P, Bendix T, et al. System influences on work disability due to low back pain: an international evidence synthesis. Health Policy 2017;121:903-12.

8 Kilgour E, Kosny A, McKenzie D, et al. Healing or harming? healthcare provider interactions with injured workers and insurers in workers' compensation systems. J Occup Rehabil 2015;25:220-39.

9 Brijnath B, Mazza D, Kosny A, et al. Is clinician refusal to treat an emerging problem in injury compensation systems? BMJ Open 2016;6:e009423.

10 Liebman JB. Understanding the increase in disability insurance benefit receipt in the United States. J Econ Perspect 2015;29:123-50.

11 Parliamentary Budget Office. Disability support pension: historical and projected trends Canberra: Parliament of Australia, 2018

12 Jensen NK, Brønnum-Hansen H, Andersen I, et al. Too sick to work, too healthy to qualify: a cross-country analysis of the effect of changes to disability benefits. $J$ Epidemiol Community Health 2019;73:717-22.

13 García-Gómez P, Gielen AC. Mortality effects of containing moral hazard: evidence from disability insurance reform. Health Econ 2018;27:606-21.

14 Barr B, Taylor-Robinson D, Stuckler D, et al. 'First, do no harm': are disability assessments associated with adverse trends in mental health? A longitudinal ecological study. J Epidemiol Community Health 2016;70:339-45.

15 Lane TJ, Collie A, Hassani-Mahmooei B. Work-Related injury and illness in Australia, 2004 to 2014. What is the incidence of work-related conditions and their impact on time lost from work by state and Territory, age, gender and injury type? 54. Melbourne, Australia: Institute for Safety Compensation and Recovery Research, 2016 
16 Bernal JL, Cummins S, Gasparrini A. Interrupted time series regression for the evaluation of public health interventions: a tutorial. Int J Epidemiol 2017;46:348-55.

17 Lane TJ, Gray S, Hassani-Mahmooei B, et al. Effectiveness of employer financial incentives in reducing time to report worker injury: an interrupted time series study of two Australian workers' compensation jurisdictions. BMC Public Health 2018;18:100.

18 Australian Bureau of Statistics. 6202.0 - Labour Force, Australia, Mar 2018. In: Australian Bureau of statistics. Canberra, Australia, 2018.

19 Centre for International Economics. Statutory review of the workers compensation legislation Amendment act 2012: final report. Canberra: Australia: The Centre for International Economics, 2014

20 Standing Committee on Law and Justice NSWP, Legislative Council. Review of the exercise of the functions of the WorkCover authority. 181. Sydney, New South Wales, 2014

21 Australian Bureau of Statistics. Australian New Zealand Standard Classification of Occupations, Version 1.2. In: Statistics ABO. Canberra: Australia: Australian Bureau of Statistics, 2013.

22 Australian Bureau of Statistics. Australian New Zealand Standard Industrial Classification, Revision 2.0. In: Statistics ABO. Canberra: Australia: Australian Bureau of Statistics, 2006

23 Australian Safety and Compensation Council. Type of occurrence classification system. 3rd ED. Australia: Australian Government, 2008.

24 Gray SE, Collie A. The nature and burden of occupational injury among first Responder occupations: a retrospective cohort study in Australian workers. Injury 2017:48:2470-7.

25 Berecki-Gisolf J, Smith PM, Collie A, et al. Gender differences in occupational injury incidence. Am J Ind Med 2015;58:299-307.

26 Cocker F, Sim MR, Kelsall $\mathrm{H}$, et al. The association between time taken to report, Lodge, and start wage replacement and return-to-work outcomes. J Occup Environ Med 2018;60:622-30.

27 Macpherson RA, Lane TJ, Collie A, et al. Age, sex, and the changing disability burden of compensated work-related musculoskeletal disorders in Canada and Australia. BMC Public Health 2018;18:758.
28 Fox J, Weisberg S. Time-Series regression and generalized least squares: an appendix an R companion to applied regression. 8. Third Edition, 2018.

29 Cowpertwait P, Metcalfe A. Introductory time series with R. New York: Springer-Verlag, 2009.

30 Lopez Bernal J, Cummins S, Gasparrini A. The use of controls in interrupted time series studies of public health interventions. Int J Epidemiol 2018:47:2082-93.

31 R: A language and environment for statistical computing. [program]; 2018.

32 RStudio: Integrated Development for R. [program]; 2018.

33 Halonen Jl, Solovieva S, Virta LI, et al. Sustained return to work and work participation after a new legislation obligating employers to notify prolonged sickness absence. Scand I Public Health 2018:46:65-73.

34 Viikari-Juntura E, Virta LJ, Kausto J, et al. Legislative change enabling use of early part-time sick leave enhanced return to work and work participation in Finland. Scand J Work Environ Health 2017;43:447-56.

35 Boden LI, Ruser JW. Workers' Compensation "Reforms," Choice of Medical Care Provider, and Reported Workplace Injuries. Rev Econ Stat 2003;85:923-9.

36 Guo Xuguang (Steve), Burton JF. Workers' compensation: recent developments in moral hazard and benefit payments. ILR Review 2010;63:340-55.

37 Cassidy JD, Carroll LJ, Côté $\mathrm{P}$, et al. Effect of eliminating compensation for pain and suffering on the outcome of insurance claims for whiplash injury. N Engl J Med 2000;342:1179-86.

38 Cameron ID, Rebbeck T, Sindhusake $D$, et al. Legislative change is associated with improved health status in people with whiplash. Spine 2008;33:250-4.

39 Lippel K. Workers describe the effect of the workers' compensation process on their health: a Québec study. Int I Law Psychiatry 2007;30:427-43.

40 Elbers NA, Collie A, Hogg-Johnson S, et al. Differences in perceived fairness and health outcomes in two injury compensation systems: a comparative study. BMC Public Health 2016;16:658.

41 Jetha A, Pransky G, Fish J, et al. Return-To-Work within a complex and dynamic organizational work disability system. J Occup Rehabil 2016;26:276-85.

42 Gray SE, Lane TJ, Sheehan L, et al. Association between workers' compensation claim processing times and work disability duration: analysis of population level claims data. Health Policy 2019;123:982-91. 